\title{
RESPEITANDO O ANTIGO SISTEMA: IRRIGAÇÃO E O CONTROLE DE ENCHENTESNA CHINA DO SÉCULO III
}

\author{
AEC1 $^{1}$
}

Débora Lopes do Rêgo ${ }^{2}$

\begin{abstract}
Resumo: A conservação dos sistemas de controle de água chineses ao longo do tempo foi variável. Em alguns desses sistemas, suas tecnologias se degradaram, em outras perduraram com impressionante estabilidade. Situado na província de Sichuan, no coração da atual República Popular da China, o sistema de irrigação conhecido como Dujiangyan (都汇堰, Düjiāngyàn) é um exemplo dos maiores sucessos da engenharia hidráulica da China Imperial. Construído no século III AEC, o Dujiangyan assumiu um papel crucial no controle das enchentes do Rio Min (岷江, Mínjiāng), na irrigação e no abastecimento de água para todo o planalto de Chengdu, e muitas de suas estruturas originais permanecem em funcionamento até os dias atuais. Este artigo, assim, tem como objetivo tratar brevemente da concepção, execução e impacto desta obra, que transformou a região em um dos pilares do Império Chinês.
\end{abstract}

Palavras-chave: Sistemas Hidráulicos; Controle dos rios; China.

\begin{abstract}
The conservation of the Chinese water control systems has been variable. Some of these works has degraded and vanished, while others have endured and resisted with outstanding stability. Located in Sichuan, at the heart of the current People's Republic of China, the irrigation system known as Dujiangyan (都江堰, Düjiāngyàn) is one of the biggest successes of Chinese Imperial hydraulic engineering. Built during the century III BCE, the Dujianggyan played a crucial role in controlling the flood waters of the Min River (岷江, Minjiāng), irrigating and supplying water throughout the Chengdu Plateu, and its foundations remain in operation until current date. This article offers to discuss briefly about the conception, the execution and the impact such a system brought, transforming the region into one of the pillars of the Chinese Empire.
\end{abstract}

Keywords: Hydraulic Systems; Water Control; China.

\section{Introdução}

A China é uma civilização muito conhecida e respeitada por suas grandes construções hidráulicas. Desde o Grande Canal, que ligava o território em sentido nortesul, à sua longa história de luta contra as terríveis enchentes do Rio Amarelo na Grande Planície, até a construção de suas famosas pontes. No século XVII, o jesuíta francês

\footnotetext{
${ }^{1}$ Este artigo foi desenvolvido no Grupo de Estudos Sobre História da Ásia, vinculado ao Departamento de História da UFPE.

${ }^{2}$ Bacharel em história pela Universidade Federal de Pernambuco, atualmente mestranda no Programa de Pós-graduação da Universidade Federal de Pernambuco. Contato: Rua José Trajano, Boa Viagem, RecifePE, Brasil. E-mail: dbr.lopes.r@gmail.com.
} 
Louis Lecomte relacionou a abundância que via no Império com a existência da rede de canais pela qual navegou. Ele não escondia sua admiração pelos engenheiros chineses:

Os chineses dizem que seu País estava originalmente totalmente inundado, e que através do trabalho eles drenaram a água ao cortar um caminho para esses canais tão úteis. Se isso for verdade, eu não posso admirar de uma só vez a audácia e a dedicação de seus trabalhadores que fizeram então grandes Rios Artificiais, e um tipo de Mar e assim foi criada as Planícies mais Férteis do mundo. ${ }^{3}$

Ele estava certo quando afirmou que a audácia e a dedicação transformaram a paisagem da China. Do topo de sua imensidão geográfica, o território chinês é cortado por inúmeros rios, riachos, lagos e corredeiras, que, em sua maioria, fluem de oeste para leste e formam um caminho natural e eficiente que tornou possível a comunicação entre as mais distantes partes da China. Onde a natureza falhou em fornecer conexões nortesul, a engenhosidade humana compensou e os chineses se destacavam dentre outros povos do mundo por sua capacidade de criação de sistemas hidráulicos para controle e uso das vias aquáticas. Tais sistemas eram o local de encontro entre o ambiente que os cercava e a cultura Han: sua resposta tanto aos desafios do clima e topografia de determinadas regiões, como eram também produto de uma demanda social e política para irrigação e para meios mais eficientes de transporte.

Na sociedade do vegetal, ${ }^{4}$ como é chamada por Pierre Gourou, a irrigação era um fator decisivo para um cultivo bem sucedido em larga escala. $\mathrm{O}$ que não faltam são exemplos na longa história chinesa que sistemas e estruturas de engenharia hidráulica e a China se destaca pelos seus conhecimentos de como lidar com a água, especialmente grandes e difíceis corpos d'água. Tempo e recursos consideráveis foram investidos no desenvolvimento de técnicas e na construção de estruturas para o controle e uso das águas por toda sua longa história. Em uma sociedade que possui duas das suas três regiões produtoras, uma em clima semi-árido e outra em terreno montanhoso, o desenvolvimento de técnicas de irrigação foi sem dúvidas uma necessidade.

\footnotetext{
${ }^{3}$ NEEDHAM, Joseph. Science and Civilization in China. Vol. 4: Physics and Physical Technology, Part III: Civil Engineering and Nautics. 1971, p. 211.

${ }^{4} \mathrm{O}$ conceito de "Civilização do vegetal" refere-se ao fato de todos os principais materiais utilizados pelos chineses serem de origem vegetal. A madeira e o bambu eram os principais materiais da construção, também eram os principais materiais na construção de barcos. Os fios com os quais confeccionavam as roupas, à exceção da seda, eram de origem vegetal também, feitos de algodão ou linho. Até o papel se popularizar, os livros eram impressos em blocos de madeira. GOUROU, Pierre. La terre et l'homme en Extrême-Orient. Paris: Flammarion, 1972, p. 26 e 27.
} 
Surpreendente é o fato de três das mais notáveis construções da engenharia hidráulica clássica sejam datados do período Qin (221 - 206 AEC): Zhengguoqu (郑国 渠, Zhèng Guó Qú) localizado na província de Shaanxi, ao norte cidade de Xi'an, o Dujiangyan (都汇堰, Düjiāngyàn) na província de Sichuan e o Canal Lingqu (灵渠, Líng Qú) próximo a Gulin na atual Região Autônoma de Guangxi. ${ }^{5}$

Os dois primeiros projetos surgiram de uma necessidade de organizar e fortalecer regiões de grande importância para o império, visando principalmente um maior desenvolvimento econômico e proteção contra enchentes, enquanto que o último foi construído para ser uma importante artéria da comunicação norte-sul que conectava o norte e o centro de forma rápida e eficiente com as regiões mais distantes do $\operatorname{sul}^{6}$ aos centros de comando. Em um território onde todas as vias fluviais corriam em sentido leste-oeste, essa comunicação "vertical", por assim dizer, foi uma das mais importantes pois permitia um rápido e eficiente deslocamento de inteligência e tropas, por consequência uma maior presença e interferência de um poder central em locais de outra forma distantes.

Todas as três obras citadas merecem seu devido reconhecimento pela engenhosidade de sua projeção: ainda que não se igualem nem à fama nem ao tamanho físico do Grande Canal, seus projetos, em sua concepção, carregam a mesma genialidade.

Sabe-se que a região do planalto de Chengdu teve um papel muito importante cultural e econômico na história da China. Conhecido como um fértil vale cercado por montanhas, o Planalto foi a primeira área do mundo a cultivar chá de maneira sistêmica. ${ }^{7}$ Também foi a primeira região, por volta da época Tang (618-907 EC) a produzir livros impressos em blocos de madeira em escala significativa e distribuí-los para o resto do Império.

O presente trabalho foi instigado pelo desenvolvimento da pesquisa que resultou na Monografia de Conclusão de Curso “Águas Temidas, Águas Desejadas”: A Gestão das Águas do Rio Amarelo do Engenheiro Pan Jixun, 1578-1593, defendida em 2016,

\footnotetext{
${ }^{5}$ JOSEPH, Needham. Science and Civilization in China. Vol. 4. Op. cit., p. 284 e 285.

${ }^{6}$ Ibidem.

${ }^{7}$ ELVIN, Mark. The retreat of the elephants: an environmental history of China. New Haven: Yale University Press, 2008. p. 59
} 
que trata da relação da cultura chinesa com o meio ambiente na região da Grande Planície do Norte e das inúmeras tentativas (e falhas) de controle do Rio Amarelo. A pesquisa trouxe atenção a outros sistemas e tentativas de controle de rios muitos radicalmente diferentes da relação que havia se construído com o Rio Amarelo ao norte.

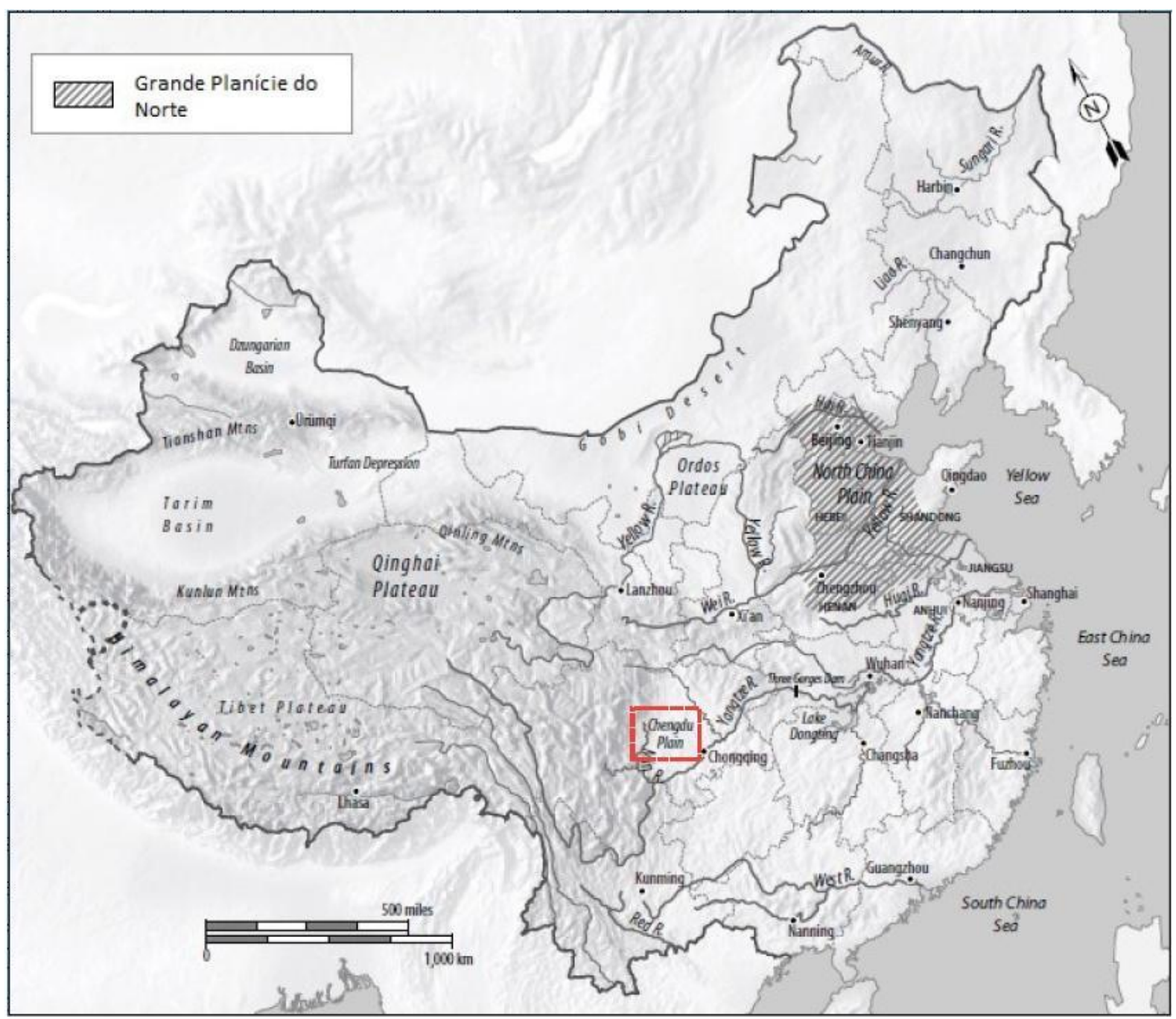

Mapa 1: Divisão geográfica da China. Em destaque, a Grande Planície do Norte (em listrado) e o Planalto de Chengdu (em vermelho). 8

Aqui, portanto, o foco sai da Grande Planície no Norte para se concentrar no vale fluvial do Yangzi e no esquema de irrigação Dujiangyan, na atual província de Sichuan (Mapa I). Situado na região central da China, seu sistema bimilenar é prova física da qualidade da engenharia clássica imperial, além de ser um exemplo

\footnotetext{
${ }^{8}$ Mapa originalmente encontrado em PIETZ, David. The Yellow River. The Problem of Water in Modern China. MA: Cambridge Press. 2015, p. xi. Modificado pela autora..
} 
extraordinário de um sistema hidráulico que se manteve sustentável e resistiu aos desafios do tempo, de repetidas destruições, e do desgaste ambiental até os dias atuais.

\section{O Oeste do Império Chinês}

O antigo império chinês tradicionalmente conta com três principais regiões que compunham o seu coração econômico, histórico e cultural. A Grande Planície do Norte; a bacia do Yangzi ao Sul; e as montanhas no Oeste, onde dois principais centros históricos se desenvolveram: o Estado de $\mathrm{Ba}$, que se situava próximo às entradas dos desfiladeiros do Yangzi, ao leste, localizava-se a uma altura de 300 a 500 metros acima do nível do mar; o segundo centro histórico, maior e mais importante, foi o Estado de Shu, se desenvolveu no meio do planalto de Chengdu, à oeste, a uma altura de 450 a 750 metros acima do nível do mar, ${ }^{9}$ tendo a cidade de Chengdu como sua capital.

A região do antigo Estado de Shu, que se localiza no coração da República Popular da China, na atual província de Sichuan, se encontra em uma posição especialmente isolada: cercada pelas montanhas do Himalaia a oeste, o acesso a essa localidade era possível pelos estreitos desfiladeiros do vale do Yangzi, a leste, ou pelas precárias rotas terrestres à noroeste que vinham do deserto. $\mathrm{O}$ isolamento geográfico se traduziu em uma relativa autonomia, e ainda que pertencesse e se reconhecesse pertencente ao Império Chinês, a história chinesa naquela região passou em um ritmo e características diferentes do resto do império e particulares a si própria.

Na segunda metade do século 3 AEC, a China estava fragmentada em pequenos estados com o declínio do controle centralizador exercido pela dinastia Zhou (1080-221 AEC). Esses estados soberanos estavam em guerra cujo objetivo final era a reunificação da China. Esse período de conflito interno ficou conhecido como Estados Combatentes (484-221 AEC).

\footnotetext{
${ }^{9}$ ELVIN, Mark. The retreat of the elephants. Op. cit.,. p. 87.
} 


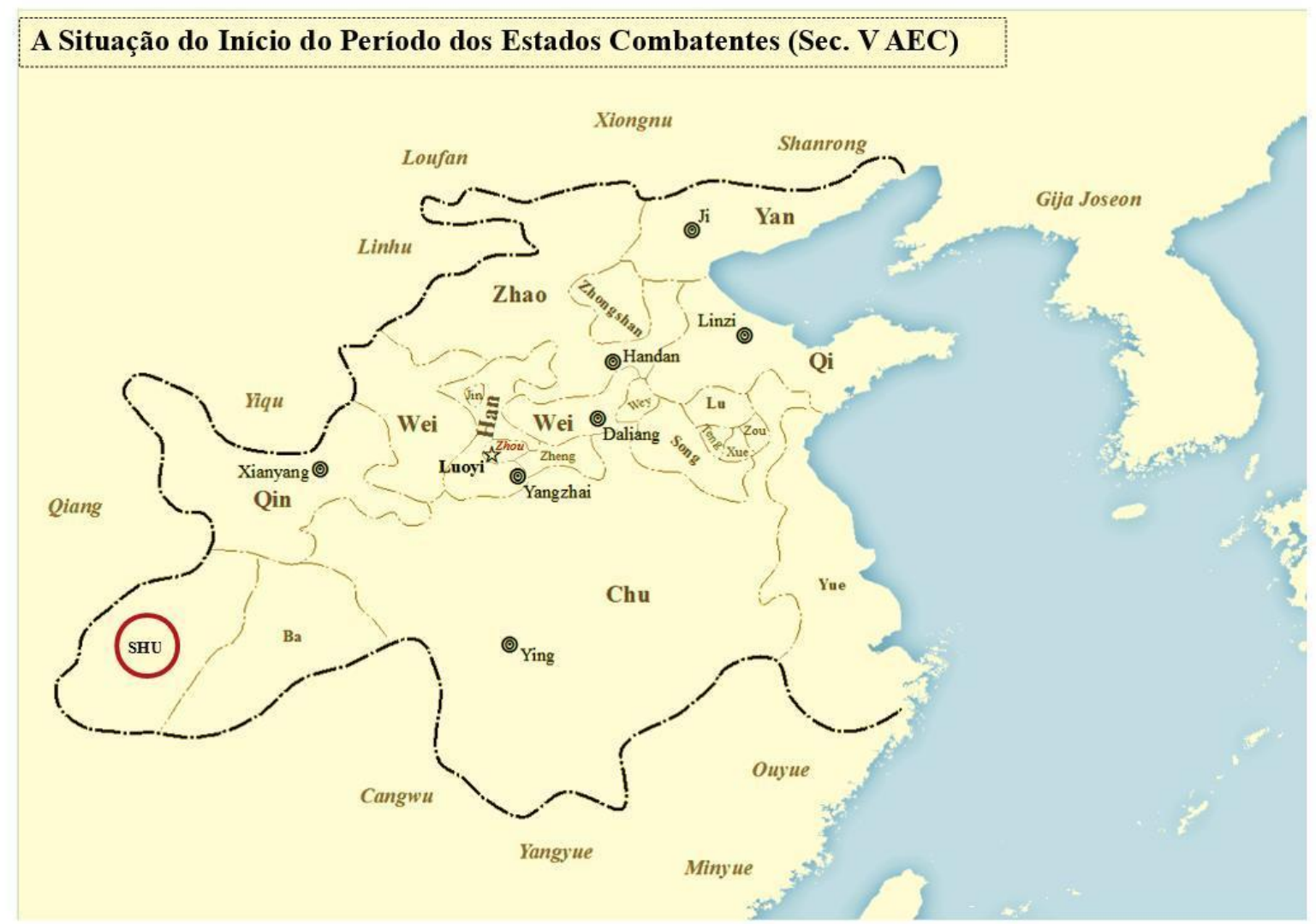

Mapa 2: Divisão política da China no Período dos Estados Combatentes. À esquerda, o reino de Shu. ${ }^{10}$

O estado Qin, a noroeste, o eventual ganhador desta corrida pelo trono, incorporou o Estado de Shu em 316 AEC. Estima-se que, em 309 AEC, um oficial Qin chamado Li Bing tenha sido designado para Shu, para inicialmente para ajudar nas fortificações da região. Deveria ser muito novo e seu trabalho deve ter progredido e deixado uma boa impressão, pois, em 250 AEC, foi nomeado governador da então província de Shu (Mapa 2). Ao conquistar e incorporar esta região, os Qin também ganharam as terras férteis do planalto de Chengdu e sua rede de canais de irrigação que levava as águas do Rio Min através do planalto para as áreas beneficiadas. Baseado nesse sistema de canais previamente existente, $\mathrm{Li}$ Bing projetou e construiu o Dujiangyan: uma grande estrutura hidráulica que visava estabilizar o Rio Min, impedir a

10 Mapa originalmente encontrado em <https://en.wikipedia.org/wiki/Warring_States_period>, modificado pela autora. 
ocorrência de enchentes e encontrar uma solução para os períodos de seca, quando as águas do rio estavam em seu nível mais baixo.

Estima-se que Li Bing não tenha vivido além dos dez primeiros anos após sua nomeação como governador da província. Também não viveu tempo o suficiente para ver seu projeto de irrigação concluído. Após a sua morte, seu filho, Li Erlang, foi o responsável por sua finalização.

\section{Rivalidades e Escolas de Pensamento}

No horizonte das Escolas do pensamento chinês, uma verdade nunca é absoluta e convive simultaneamente com outras interpretações que existam ou possam vir a existir. ${ }^{11}$ As contradições não são irredutíveis e excludentes, mas sim alternativas que podem ser consideradas, e cuja transição de um para outro ocorre quase que despercebida. As diferentes escolas de pensamento nada mais são do que diferentes formas de expressão da mesma ideia. ${ }^{12}$

Dentre as alternativas que mais se destacaram e se desenvolveram, podemos enfatizar duas grandes escolas de pensamento que dominaram o cenário das técnicas usadas nos controles dos rios: a Taoísta e a Confuciana. Ambas eram dois dos mais importantes pilares do pensamento chinês e permearam não apenas os fundamentos do pensar chinês, mas encontraram expressões em todas as facetas da cultura chinesa, como a política, a relação familiar e a relação dos chineses com a morte.

Também o conhecimento não deveria ser apenas teórico, mas sim praticado e executado. O desenvolvimento de ideias e novas propostas teóricas acabavam por ser traduzidas em modelos sociais, econômicos e culturais e não apenas objetos de contemplação. Nada mais prático e mais simbólico de toda essa concepção do que transformar esse conhecimento em estruturas hidráulicas.

Por um lado, a técnica taoísta se caracterizava por defender que a menor quantidade de intervenção possível nas estruturas naturais dos rios era a melhor abordagem para controlá-lo. O almejado equilíbrio consistia em deixar a natureza seguir seu próprio curso. Baseado nesses princípios, as estruturas construídas deveriam

\footnotetext{
11 CHENG, Anne. História do Pensamento Chinês. Petrópolis: Vozes, 2008, p. 3

12 BROOK, Timothy. The Troubled Empire. London: Harvard University Press, 2010, p. 162.
} 
respeitar a geografia local e seguir seu fluxo, se moldar a elas. Os diques deveriam ser baixos, preferencialmente posicionados a certa distância das margens para dar conta dos volumes excedentes de água em época de cheias. O ideal era que o leito fosse limpo com certa regularidade para combater os efeitos do assoreamento do canal.

A técnica taoísta encontrava forte respaldo no mito de $\mathrm{Yu}$, o Grande (夏禹, Xià Yǔ). Segundo Sima Qian (司馬遷, Sīmă Qiān) - o grande historiador da época da dinastia Han (206 AEC - 220 EC) - dentre os mitos de criação que constituem o imaginário chinês, Yu teria sido o último dentre cinco Sábios Imperadores responsáveis pela criação dos elementos que formavam as bases da civilização chinesa: a escrita, a agricultura, o Estado, os calendários e a virtude moral do governo. $\mathrm{Na}$ lenda, ele teria sido capaz de controlar as águas do Rio Amarelo, um dos mais turbulentos e desafiadores rios para a engenharia hidráulica chinesa desde os inícios de sua civilização. Sua grande vitória consistiu em ter conseguido com que a correnteza do Rio Amarelo voltasse para seu curso original ao escavar o leito do rio e construir diques em suas margens, salvando assim a Grande Planície do Norte de terríveis enchentes.

$\mathrm{O}$ contexto literário em que o conto de $\mathrm{Yu}$, o Grande foi reproduzido, no entanto, chama a atenção, como aponta David Pietz:

\begin{abstract}
Mitos sobre enchentes são frequentemente mitos de recriação que são formulados após contos de criação humana (o mito original da criação). Tais contos são sancionados "pela existência de um corpo de práticas que são centrais para o povo que cria o mito". Dois temas adicionais desses mitos centram na enchente como uma forma de punição ou de repúdio a um passado imediato e na água como ideia principal dos mitos de recriação (ex.: como oposto ao fogo ou outros eventos naturais cataclísmicos). É significativo notar que nesses mitos recentes, a água é representada alternadamente como uma força destrutiva ou construtiva, ou como um símbolo de caos ou ordem. ${ }^{13}$
\end{abstract}

Se o mito de Yu era sancionado por uma série de práticas cultivadas pela cultura chinesa, o mito certamente sancionou a existência das práticas de engenharia taoístas e eram frequentemente um forte argumento. Porém suas técnicas aplicadas nem sempre eram eficazes, e acabavam por dar espaço para que os defensores das técnicas de bases confucianas.

\footnotetext{
${ }^{13}$ PIETZ, David. The Yellow River. The Problem of Water in Modern China. MA: Cambridge Press. 2015. p. 30.
} 
Diferentemente dos taoístas, os confucianos defendiam uma intervenção muito mais dura e assertiva sobre a natureza. O equilíbrio era alcançado através da imposição. Quanto às estruturas hidráulicas, também defendiam a limpeza dos leitos dos rios através da escavação para combater o assoreamento. Mas os diques que cercavam as margens deveriam ser estreitos, pois aumentando a pressão na correnteza aumentava também a força da água e a sua capacidade de transportar sedimentos até o mar e evitar o assoreamento dos canais. Os diques deveriam ser altos e grossos, para conter o volume de água das enchentes.

O favorecimento e a aplicação de cada uma das concepções de gestão das águas dependiam do funcionário responsável pela concepção e execução das obras. Mas, se a execução de uma determinada técnica acabaria por ser bem-sucedida em resolver quaisquer que fossem os problemas que afligiam o rio, ou mesmo se tal técnica era condizente o suficiente com a geografia local para que a estrutura fosse sustentável e duradoura, isso dependia de cada caso.

\section{Dois casos icônicos e extremos são os do Rio Amarelo e do Rio Min.}

O caso do Rio Amarelo talvez seja o mais icônico do relacionamento dos chineses com seus rios. Situado em uma região semi-árida, suas águas cortam através de um planalto de losse, um solo fértil, porém facilmente erodido. A quantidade de sedimentos carregados na correnteza transforma a cor das águas e justifica o nome de "Amarelo". O assoreamento do canal à medida que o rio avança em direção ao mar, ao longo do tempo, foi o responsável pela formação de uma das regiões mais férteis da China: a Grande Planície do Norte. O mesmo loesse responsável pela grande produtividade da região, também é um grande problema: esse solo facilmente maleável forma margens frágeis, incapazes de resistir a grandes pressões d’água sem se desfazer.

Assim que o Rio Amarelo, afligido por chuvas irregulares, e com elas imprevisíveis mudanças no nível e na força de sua correnteza, rompia e transbordava suas margens com uma facilidade quase assustadora. Para piorar a situação, a velocidade com a qual o canal assoreava acabava por causar a formação de bancos de areia que, eventualmente, obstruíram a passagem das águas e por fim, causavam desastrosas enchentes. A destruição que ele deixava em seu rastro dificilmente encontra paralelos em outros lugares, principalmente por se tratar de uma região de grande 
presença populacional. As enchentes provocavam grande quantidade de mortes, destruía as plantações em seus caminhos. Após a enchente, com a perda de suas colheitas, os sobreviventes sofriam penosos períodos de fome. Irônico que o mesmo fenômeno responsável por tanto sofrimento da população local também fosse o mesmo responsável pela renovação cíclica da fertilidade da Grande Planície: ao transbordar de seu canal, o losse levado pelas águas do rio renovava o solo, depositando uma nova camada de terra fértil. Não é à toa que o Rio Amarelo recebesse títulos tanto de "Celeiro da China" como de "Tristeza da China".

Nenhuma das técnicas, até o final do período imperial, conseguiu domar o Rio Amarelo de forma satisfatória e resolver seus problemas a longo prazo. Qualquer método utilizado, fosse taoísta ou confuciano, ainda que funcionasse por um período de tempo, acabava por se desgastar e criar novos problemas. Por todo o período imperial chinês, ambas as técnicas se revezaram sem que nenhuma realmente fosse bemsucedida ou sustentável por um grande período de tempo. ${ }^{14}$

No caso do Rio Min, como será discutido mais a fundo, a técnica escolhida foi um sucesso desde sua primeira concepção. $\mathrm{O}$ rio em questão estava inserido em um contexto geográfico muito diferente do Rio Amarelo, e Dujiangyan demonstrou um perfeito funcionamento não apenas na sua estrutura, mas na interação da mesma com o meio onde foi construída, se mostrando uma obra eficaz e sustentável.

\section{O Sistema de Irrigação Dujiangyan}

Esse local, antes conhecido como o reino de Shu, é uma região de clima de monção subtropical que tem altos índices de precipitação durante o verão; o Planalto de Chengdu, especificamente, é em uma área onde tanto águas fluviais quanto águas subterrâneas são abundantes. ${ }^{15} \mathrm{~A}$ cadeia de montanhas que a cerca ao norte, ajuda na

\footnotetext{
${ }^{14}$ LOPES, Débora. "Águas Temidas, Águas Desejadas": A Gestão das Águas do Rio Amarelo do Engenheiro Pan Jixun, 1578-1593. p. 48 e 49.

${ }^{15}$ CAO, Shuyou; LIU, Xingnian; ER, Huang. "Dujiangyan Irrigation System - a world cultural heritage corresponding to concepts of modern hydraulic science". Journal of Hydro-environment Research, v. 4, n. 1, 2010, p. 6.
} 
proteção contra massas de ar polares durante o inverno e a água que escoa delas garante que a oferta da mesma seja abundante durante o verão. ${ }^{16}$

Seu curso d'água mais importante é o Rio Min (岷江, Mínjiāng), um dos principais afluentes do Yangzi. Tradicionalmente, acreditava-se que se tratava do canal principal do Yangzi que descia pelo planalto de Chengdu, porém, mais tarde, percebeuse que esse não era o caso, mas que era ele um grande afluente do grande rio do Sul da China. O Min é um rio com pouca variação na sua correnteza anual e, sob condições hidrológicas normais, ele é capaz de fornecer água para atender as demandas de consumo do sistema de irrigação Dujiangyan (Figura 1) sem maiores problemas. ${ }^{17}$

Figura 1: Esquema do sistema Dujiangyan. ${ }^{18}$

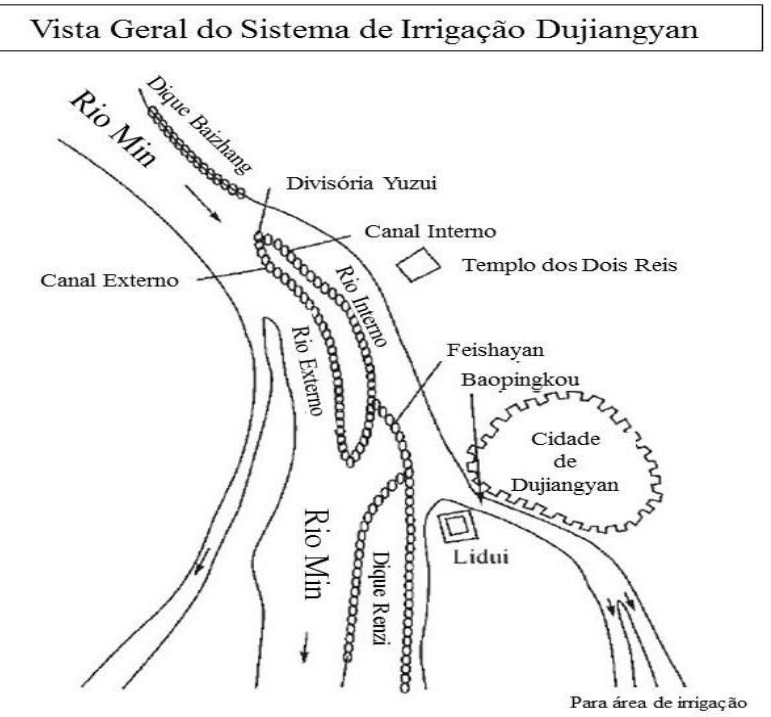

A própria localização do projeto hidráulico é perfeita para o papel que se propôs a desempenhar: construído no ponto mais alto do planalto aluvial, cerca de 734 metros acima do nível do mar, ideal para controlar e distribuir água para irrigação fazendo uso apenas da força da gravidade. ${ }^{19} \mathrm{O}$ planalto tem uma inclinação que permite a água de ser

\footnotetext{
${ }^{16}$ ELVIN, Mark. The retreat of the elephants. Op. cit., p. 58.

${ }^{17}$ CAO, Shuyou; LIU, Xingnian; ER, Huang. "Dujiangyan Irrigation System-a world cultural heritage corresponding to concepts of modern hydraulic science". Op. cit., p. 6.

${ }^{18}$ Mapa originalmente encontrado em LI, Keke; XU, Zhifang. "Overview of Dujiangyan Irrigation Scheme of ancient China with current theory". Irrigation and Drainage, v. 55, n. 3, 2006, p. 293. Traduzido pela autora.

${ }^{19}$ Idem, p. 292.
} 
transportada sem precisar de nenhum tipo de bombeamento. Os canos, construídos seguindo a configuração geográfica local permitem que a água flua de modo a não ficar eventualmente presa ou pare dentro dos canos.

Originalmente, o projeto do Dujiangyan contava com três elementos principais: Yuzui, a barreira responsável pelo desvio da correnteza para dentro do sistema interno de irrigação e separa o Canal Interno do Canal Externo; Fishayan, o vertedouro; e Baopingkou, a abertura que leva a água do sistema de Dujiangyan para os canais que distribuem a água para a irrigação propriamente.

A correnteza do Rio Min ao chegar no sistema é dividida pelo Yuzui, um dique originalmente construído com várias camadas de grandes "cestos" de bambu com cerca de 10 metros de largura e 0,5 metros de diâmetro, preenchidos com grandes cascalhos para fazer peso. Essa divisória conduzia parte da água e dividia o rio em dois canais: o Canal Interno (Nèi Jiāng) e o Canal Externo (Wèi Jiāng). A corrente desviada para o Canal Interno era inteiramente direcionada para a irrigação: as águas do Min eram levadas através do canal diretamente para outro que tinha ligação direta com a extensa rede de canais de irrigação que se espalhava pelo planalto de Chengdu.

Esse canal com ligação direta com a rede de distribuição da água é chamado de Baopingkou. Diz-se que o Baopingkou foi a parte mais difícil e mais importante de ser construído, pois foi preciso escavar através de uma colina de solo muito duro e pedregoso. A técnica usada pelas pessoas envolvidas na construção, assim, conta-se que foi a seguinte: eles faziam pequenos buracos na rocha, onde colocavam gravetos e neles tocavam fogo. ${ }^{20}$ Uma vez bem aquecida, prontamente jogavam água fria para rapidamente resfriá-la e quebrá-la com o choque térmico e assim por diante abrindo um buraco cada vez maior. E então o Baopingkou - que significa "boca de uma garrafa preciosa" - foi escavado e a conexão do Rio Min com a área irrigada garantida. Parte da montanha ainda existe, um lugar chamado "colina partida" ou "colina separada", onde depois foi construído um templo taoísta.

Também ao longo do Canal Interno, registros históricos descrevem a presença de pelo menos três estátuas de pedra, posicionadas em diferentes locais, que

\footnotetext{
${ }^{20}$ Ibidem.
} 
funcionavam como medidores de correnteza. ${ }^{21}$ Uma dela, diz-se, estava próxima ao Baopingkou. Se a água chegasse ao nível dos pés da estátua, este era um indicativo de um período de seca. Porém, se a água ao contrário atingisse o nível dos ombros das estátuas, este apontava para uma enchente prestes a ocorrer e estava na hora de acionar o Feishayan para que o Canal Interno não transbordasse.

Já a corrente direcionada para o Canal Externo seguia o antigo curso original do Rio Min. É ele o responsável pela maior parte do transporte de barcos nesta fluvial. Mais importante, o Canal Externo é utilizado como um canalizador para o excesso de água e sedimentos do Canal Interno - possuindo uma capacidade de transporte de volume d'água consideravelmente menor - que é transferida através do Feishayan, o vertedouro localizado próximo à parte final da barreira do Yuzui e é o mais importante mecanismo de regulação de toda a estrutura. Quando o nível da correnteza do Canal Interno sobe acima de um ponto fixo predeterminado, o excedente d'água transborda pelo Feishayan para o Canal Externo juntamente com boa parte dos sedimentos que o rio carrega.

Embora o sistema de irrigação Dujiangyan tenha sido concebido e executado por um funcionário imperial e seu filho, a construção do projeto foi de grande participação dos camponeses locais, assim como eles também tiveram uma grande participação no processo de manutenção da estrutura hidráulica.

Primeiramente, os materiais usados na construção foram todos retirados do local. Varas e cestos de bambu, vigas de madeira, cascalho, pedras. Todos esses materiais usados no projeto original podiam ser encontrados nas proximidades, e eram eles também utilizados nos processos de manutenção. ${ }^{22}$ Tudo isso facilitava a execução de toda a rotina estabelecida ao longo do ano para manter a estrutura em bom estado. Também em casos de emergência os materiais poderiam ser facilmente extraídos nos arredores e fabricados sem muitos transtornos.

Os reparos anuais começavam em outubro: quando o nível de água era menor, o fluxo do rio para o Canal Externo era interrompido e toda a água se concentra totalmente no Canal Interno, desviando por um período de tempo toda a água do rio para a irrigação. Nesse momento, o Canal Externo recebia quaisquer reparos que

\footnotetext{
${ }^{21}$ Idem, p. 296.

${ }^{22}$ Idem, p. 297.
} 
viessem a ser necessários e o seu leito era escavado até uma profundidade já preestabelecida.

Em fevereiro, durante o inverno quando o fluxo de água é maior, a barreira que fechava o Canal Externo era levantada e, dessa vez, reposicionada para bloquear o Canal Interno, encerrando o acesso da água aos canais de irrigação e, por consequência, encerrando também a época do cultivo. Pelos próximos dois meses, o Canal Interno passa pelo mesmo tratamento oferecido ao Canal Externo para que, em abril, as barragens seriam finalmente levantadas dando início à um novo ciclo de cultivo.

\section{Efeitos e Consequências}

Toda a vida econômica da região do Sichuan, por consequência, começou a girar em torno do esquema do Dujiangyan. Não apenas para um simples controle das cheias sazonais que afligiam a região, mas o desenvolvimento que a obra trouxe contemplou também outras tecnologias atraídas pela prosperidade da região. Needham cita "moinhos d'água para descascar e moer arroz" e "maquinarias, em números de dezenas de milhares, estavam estabelecidas ao longo dos canais". ${ }^{23}$

Mais de uma vez, a região foi descrita como um grande e fértil jardim em meio às montanhas, e certamente devia ao seu grande sistema de irrigação para atribuir toda essa prosperidade.

A história do sistema Dujiangyan pode ser dividida em três períodos: o período da construção original, um período de desenvolvimento e expansão, e um período moderno.

O período da construção original por Li Bing, que foi abordado no tópico acima, foi da metade do século III AEC até o início do mesmo século, por volta de 206 AEC, quando a obra foi finalmente concluída, um processo que levou quase cinquenta anos para ser finalizado.

O segundo período é o mais longo, de 206 AEC e se estendeu até a década de 1930. Conhecido como o período da expansão, ${ }^{24} \mathrm{o}$ sistema de irrigação foi sendo

\footnotetext{
${ }^{23}$ NEEDHAM, Joseph. Science and Civilization in China. Op. cit., p. 296.

${ }^{24}$ CAO, Shuyou; LIU, Xingnian; ER, Huang. "Dujiangyan Irrigation System-a world cultural heritage corresponding to concepts of modern hydraulic science". Op. cit., p. 24.
} 
gradualmente melhorado e teve sua área de irrigação expandida. Também foi um momento desafiador, onde a estrutura hidráulica foi severamente comprometida por quatro vezes:

1) em 910 EC, devido a uma enchente violenta e inesperada;

2) entre os anos de 1235 e 1267 EC, durante a conquista da China pelo império Mongol;

3) entre 1644 e 1681, na guerra em Sichuan durante os esforços da dinastia Qing manchu para conquistar o império da dinastia Ming;

4) por fim, em 1933, durante uma enchente relâmpago causada pelo rompimento de barragens rio acima ocorrido devido a um terremoto na região.

Ainda assim, apesar das destruições catastróficas, seja por motivos da natureza ou por situações causadas pelo homem, o Dujiangyan foi rapidamente recuperado ${ }^{25}$ mantendo as linhas traçadas pelo desenho original e seguindo sempre as instruções de manutenção deixadas por Li Bing.

As mais importantes mudanças trazidas pelo período moderno, a partir da década de 1940, foi o investimento em estudos e experimentos da capacidade hidroenergética do Rio Min, ${ }^{26}$ principalmente em regiões à montante, e a substituição dos materiais usados tradicionalmente na construção e manutenção do sistema por materiais mais modernos e resistentes, como concreto, por exemplo.

Além disso, o sistema de irrigação também deixou uma importante marca na dinâmica cultural de Sichuan. Todos os anos, seguindo a tradição que aparenta remontar a época de sua construção, em abril, quando acabam todos os processos de manutenção e o canal está pronto para iniciar um novo ciclo de trabalhos, há um grande festival para celebrar o levantamento da barragem e a reabertura do canal.

Seus idealizadores viraram seres lendários e sagrados na cultura tradicional local, tanto Li Bing quanto Li Erlang foram postumamente homenageados pelos trabalhos prestados à população local. Na lenda, Li Erlang é considerado um domador de dragões, uma denominação que muitos imperadores chineses recebiam ao serem

\footnotetext{
${ }^{25}$ Idem, p. 7.

${ }^{26}$ Idem, p. 5.
} 
considerados restauradores do equilíbrio e da harmonia e controladores das águas. Sobre o assunto, nada melhor do que o relato do próprio Joseph Needham, que visitou o sistema de irrigação em meados do século XX:

Eu estava em Dujiangyan em 1943, os contrastes eram profundamente impressionantes, pois bastões de incenso estavam brilhando no templo de Li Bing na frente de sua estátua impressiva, cuidada por um amigável monge taoísta, porém no pátio secundário estavam numerosos modelos das melhorias planejadas no sistema - uma barragem de controle com grandes portões ao invés do nariz de peixe [Yuzui], estações de força e assim em diante. O tempo de Li Erlang providenciava acomodação para os engenheiros, sua beleza de modo algum diminuído, enquanto que um templo menor dedicado a Yu, O Grande, acomodava a Agência de Conservação da Água. Considerando que apesar de inicialmente ter sido devido a alguma superstição e ignorância dentre as massas, o culto em Dujiangyan parece demonstrar um dos aspectos mais atraentes da cultura chinesa, especialmente aquela sintese entre Confucianismo e Taoísmo na qual, qualquer que seja a crença em deuses e espíritos, honras divinas eram certamente devidas, e pagas, aos grandes benfeitores da humanidade. ${ }^{27}$

\section{Conclusão}

A região do antigo Estado de Shu é sem dúvida uma área peculiar da história da China: ainda que estivesse politicamente, economicamente e culturalmente integrada ao Império, ao mesmo tempo, seu isolamento geográfico a forçava a um nível de autonomia que a colocou de certa forma à parte. Para auxiliar seu desenvolvimento, Sichuan até as forças da natureza parecem ter estado a seu favor: localizado no sopé do Himalaia, porém protegido por montanhas, em meio à um planalto de solo fértil e banhado por um rio previsível e sem muitos problemas com assoreamento. Não foi por acaso que a região se desenvolveu para ser considerada um dos três pilares da economia da China imperial e um de seus principais núcleos culturais.

Claro que os benefícios que a população local desfrutou não ficam atrás nem menos importante do que os do governo imperial. E elas não se limitavam à proteção contra as cheias, mas uma série de organizações e tecnologias desenvolvidas e utilizadas que acabaram por beneficiar muitos.

As manutenções dos canais de irrigação menores que cortavam por dentro das propriedades dos agricultores eram responsabilidade de cada usuário daquela terra, que deveriam inspecionar e manter seus canais em bom estado. Para os canais principais, mutirões, normalmente fiscalizados por algum oficial do governo local, eram

\footnotetext{
${ }^{27}$ NEEDHAM, Joseph. Science and Civilization in China. Op. cit., p. 296.
} 
organizados para a execução das tarefas. Tais manutenções formavam, na verdade, um longo ritual que se estendia através das estações e finalizavam com o grande festival de abril.

O fato de que os ensinamentos deixados pelos construtores desta obra permaneceram executados ao longo dos séculos se deve parcialmente ao fato do Rio Min não ser um corpo d'água tão difícil de lidar. A relativa previsibilidade de sua correnteza e a baixa quantidade de sedimentos que ele carrega contribuem para que a estrutura permaneça possível de ser mantida e sustentada com o conhecimento e forças locais. Se houvesse algo como uma estrutura que representasse perfeitamente os ideais defendidos pelos funcionários de veia taoísta, o Dujiangyan sem dúvida seria ela.

Lenda ou não, os ensinamentos e conselhos deixados desde épocas remotas permaneceram, e o sistema de irrigação Dujiangyan continua fiel aos princípios de sua fundação e baseado nela, tem se expandido pelos séculos após sua conclusão inicial. Como diz Mark Elvin, este sistema se mostrou um campeão entre outros esquemas de irrigação por sua sobrevivência, ${ }^{28}$ o que sem dúvida o coloca entre um dos mais marcantes e mais relevantes trabalhos hidráulicos da história.

\section{Referências biblíograficas}

BROOK, Timothy. The Troubled Empire. London: Harvard University Press, 2010.

CAO, Shuyou; LIU, Xingnian; ER, Huang. "Dujiangyan Irrigation System - a world cultural heritage corresponding to concepts of modern hydraulic science". Journal of Hydroenvironment Research, v. 4, n. 1, 2010.

CHENG, Anne. História do Pensamento Chinês. Petrópolis: Vozes, 2008.

ELVIN, Mark. The retreat of the elephants: an environmental history of China. New Haven: Yale University Press, 2008.

GARCÍA-NOBLEJAS, Gabriel (ed.): China: Pasado y presente de una gran civilización. Madrid: Alianza, 2012

GERNET, Jacques. O mundo chinês: uma civilização e uma história. Vol. 1. Lisboa: Edições Cosmos, 1974.

GOUROU, Pierre. La terre et l'homme en Extreme-Orient. Paris: Flammarion, 1972.

LI, Keke; XU, Zhifang. "Overview of Dujiangyan Irrigation Scheme of ancient China with current theory". Irrigation and Drainage, v. 55, n. 3, 2006.

${ }^{28}$ ELVIN, Mark. The retreat of the elephants. Op. cit., p. 122. 
LOPES, Débora. “Águas Temidas, Águas Desejadas": A Gestão das Águas do Rio Amarelo do Engenheiro Pan Jixun, 1578-1593. Monografia apresentada para obtenção do diploma de Bacharela em História pela Universidade Federal de Pernambuco, setembro de 2016.

NEEDHAM, Joseph. Science and Civilization in China. Vol. 4: Physics and Physical Technology, Part III: Civil Engineering and Nautics, 1971.

PIETZ, David. The Yellow River. The Problem of Water in Modern China. MA: Cambridge Press, 2015.

WILLMOTT, W. E. "Dujiangyan: Irrigation and Society in Sichuan, China". The Australian Journal of Chinese Affairs, n. 22, 1989. 